\title{
Nucleus circularis and lateral preoptic regulation of osmotic thirst
}

\author{
F. LAYNE WALLACE and ERNEST H. HARRELL \\ North Texas State University, Denton, Texas
}

\begin{abstract}
Small bilateral lesions of the nucleus circularis in rats produced a deficit in osmotic thirst, whereas subjects with similar-sized lesions of the lateral preoptic hypothalamus were almost identical to sham-operated rats in response to an osmotic challenge. Therefore, osmosensitive cells probably are more concentrated in the area of the nucleus circularis than in the lateral preoptic area. However, moderate-sized lesions in the lateral preoptic area resulted in a deficit in osmotic thirst, particularly when the damage was posterior to the anterior commissure. This research suggested that osmosensitive cells are diffusely represented in the preoptic area but become more concentrated in the anterior hypothalamus. This conclusion raised questions about the functional importance of the preoptic for osmoregulation and pointed to a more critical role for the nucleus circularis.
\end{abstract}

To explain the increased water retention and increased antidiuretic hormone release following injections of hypertonic saline into the blood supply of the diencephalon, Verney (1947) suggested that osmoreceptors existed in the vascular bed of supraoptic nucleus of the hypothalamus. These osmoreceptors were proposed by Verney to be located in the supraoptic and paraventricular nuclei, which both produced antidiuretic hormone. Later evidence suggested that hypothalamic osmoreceptors existed in the lateral preoptic, medial preoptic, anterior, and lateral nuclei (Andersson, 1971; Andersson, Leksell, \& Lishajko, 1975; Blass \& Epstein, 1971; Brody \& Johnson, 1980; Buggy \& Johnson, 1979; Coburn \& Stricker, 1978; Gemert, Miller, Carey, \& Moses, 1975; Johnson \& Buggy, 1977; Malmo \& Mundl, 1975; Peck \& Blass, 1975; Peck \& Novin, 1971; Teitelbaum \& Epstein, 1962; Tondat \& Almli, 1976). The implication of these studies was that osmoreceptor cells were diffusely represented in areas extending outside that of the supraoptic nuclei; however, specific populations were proposed to respond to different internal changes or to have different functions, such as control of antidiuretic hormone release, water intake, or both (Andersson, 1971; Peck \& Novin, 1971).

Interpretation of the research of hypothalamic osmoreceptors has been difficult. In many studies, it was unclear whether the neural areas being studied contained receptor cells or neurons receiving their efferents (Hatton, 1976; von Euler, 1953). In several studies, the large lesions required to produce a deficit in osmotic thirst damaged many hypothalamic areas, leaving open the possibility of restricted pathways or

Reprints may be obtained from E. H. Harrell, Department of Psychology, North Texas State University, P.O. Box 13587, NT Station, Denton, Texas 76203. concentrated, rather than diffusely distributed, osmosensitive cells. This alternative was supported by single-cell recordings following intracarotid injections of hypertonic saline, which showed that the greatest density of selectively osmosensitive cells was in the supraoptic and paraventricular areas (Cross \& Green, 1959). The present study focuses on a small structure in the anterior hypothalamus between the supraoptic and paraventricular nuclei, which has been named the nucleus circularis (Peterson, 1966).

In the rat, the nucleus circularis is a group of 260280 closely packed, magnocellular, myelin encapsulated, monopolar neurons arranged in a rostrocaudal, tube-like shape surrounding a capillary. It has unmyelinated axons that project to the supraoptic nucleus or join axons from the paraventricular nucleus that extend into the neurohypophysis (Bandaranayake, 1971; Sherlock, Field, \& Raisman, 1975). The paraventricular, circularis, and supraoptic nuclei originated from a common set of neurons phylogenetically (Bandaranayake, 1971). Because of its proximity to the supraoptic and paraventricular nuclei, the nucleus circularis had earlier been called the accessory supraoptic nucleus or nucleus paraventricularis pars lateralis (Peterson, 1966). Also, the nucleus circularis has been observed in humans and dogs (Gregoretti, 1954; Laqueur, 1954).

Two studies have reported cellular changes that indicated increased neurosecretory activity in the nucleus circularis and supraoptic following water deprivation in rats (Hatton, 1976; Tweedle and Hatton, 1976). Differences in the responses of these areas seemed to indicate more rapid changes in the nucleus circularis than in the supraoptic. Unilateral electrical stimulation of the nucleus circularis also produced a decrease in urine flow, implying an in- 
crease in antidiuretic hormone secretion. This increase may have been mediated by connections to the supraoptic or via a direct pathway to the pituitary (Bandaranayake, 1971).

Based on these data and on the unique structural characteristics, which suggested sensory function, Hatton (1976), in proposing that the nucleus circularis was an osmoreceptor, noted that the nucleus circularis met all of the criteria for a receptor except for the demonstration of generator potentials following water deprivation. Hatton stated that a receptor had to be in an area where lesions produced upsets in osmotic control, and noted that lesions in the general area of the nucleus circularis produced urinary loss but that the large size of these lesions made interpretation difficult. He speculated that only complete bilateral destruction would be effective, even though the nucleus circularis would be very difficult to hit with lesions small enough to be confined to this area.

Harrell, Lambert, and Ivy (1978) produced disruption of osmotic control with discrete lesions in the area of the nucleus circularis. These authors made extremely small lesions in the area of the nucleus circularis of rats, and found a decrease, relative to sham-operated animals, in the difference scores produced by subtracting the amount of water consumed following intraperitoneal injection of isotonic saline from the amount consumed following a similar injection of hypertonic saline. In fact, difference scores for the sham-operated animals increased for up to $60 \mathrm{~min}$, whereas those of the lesioned subjects showed little or no change. These data supported the hypothesis that osmoreceptor cells were highly concentrated in the area of the nucleus circularis. Also, the use of difference scores insured that any reduction in drinking following osmotic challenge was not simply indicative of a general response deficit.

Harrell et al. (1978) were the first to report deficits in osmotic thirst following such small lesions in the area of the nucleus circularis. If osmoreceptors are actually more concentrated in this area, then small lesions in other hypothalamic areas would not be expected to produce a response deficit comparable to that following damage in the area of the nucleus circularis. Thus, subjects with similar-sized lesions in another hypothalamic area would provide a good comparison for a nucleus circularis lesioned group. The present study was a replication and extension of Harrell et al. (1978), with the addition of a control lesion group. The preoptic area was selected as the site for control lesions, even though many studies have shown deficits in osmotic thirst following lesions of both the preoptic and lateral hypothalamic areas (Blass \& Epstein, 1971; Peck \& Novin, 1971; Teitelbaum \& Epstein, 1962). The lateral hypothalamus was not selected, because this area appears to be more involved with motor functions in drinking behavior than with osmoreception (Coburn \& Stricker, 1978; Tondat \& Almli, 1976).

\section{EXPERIMENT 1}

The purpose of Experiment 1 was to assess the effects of small lesions of the nucleus circularis and lateral preoptic area on osmotic thirst. It was hypothesized that a group of rats given discrete lesions in the area of the nucleus circularis would show a greater deficit in osmotically induced thirst than would lateral preoptic lesioned or sham-operated rats.

\section{Method}

Subjects. The subjects were 30 male, approximately $350-\mathrm{g}$, albino Sprague-Dawley rats obtained from Harlan SpragueDawley, Madison, Wisconsin. The animals were individually housed and had ad-lib access to food and water except for the $2 \mathrm{~h}$ before testing.

Procedure. By random assignment, the subjects were divided equally into a nucleus circularis lesioned group, lateral preoptic lesioned group, and sham-operated group. Surgery was performed following anesthesia produced by intraperitoneal injection of $50 \mathrm{mg} / \mathrm{kg}$ of sodium pentobarbitol. Postsurgery edema was controlled by intraperitoneal injection of $.30 \mathrm{cc}$ of atropine sulfate. Bilateral lesions were produced by passing a $1-\mathrm{mA}$, anodal current through a $.20-\mathrm{mm}$-diam electrode for $2 \mathrm{sec}$. Coordinates for lateral preoptic nucleus lesions were $9.0 \mathrm{~mm}$ anterior to the intraaural plane, $7.3 \mathrm{~mm}$ below the surface of the dura mater and $1.5 \mathrm{~mm}$ lateral to the center of the sagital sinus. Lesions in nucleus circularis animals were placed $1.8 \mathrm{~mm}$ posterior to bregma, $.9 \mathrm{~mm}$ lateral to the center of the sagital sinus, and $7.5 \mathrm{~mm}$ below the surface of the dura mater. The sham-operated group received the same treatment as the nucleus circularis group, except that the electrode was lowered to a point $1 \mathrm{~mm}$ above the area of the nucleus circularis ( $6.5 \mathrm{~mm}$ below the dura) and no current was passed.

Two weeks postsurgery, half of the animals in each group received an intraperitoneal injection of $.75 \mathrm{M} \mathrm{NaCl}$ using a 5 -cc syringe with a .5-in, 27-ga. needle (Martin, Geiselman, \& Novin, 1979). The volume injected was $1 \%$ of each animal's body weight; for example, a 350-g rat would be injected with $3.5 \mathrm{cc}$. Rats in the other half of each group received a similar volume of isotonic saline. Four days later, a reversal of this procedure was performed; that is, subjects received the opposite saline injection from that initially tested. The order of injection was counterbalanced across groups, as was the cage position in the housing rack. Immediately following injection, a drinking tube, graduated to $1 \mathrm{ml}$, was placed on the subjects home cage. Water consumption was measured in six 10-min intervals. Measurements were made from 12:00 noon to 1:00 p.m.

Following testing, the animals were sacrificed, using ether, and then perfused intracardially with isotonic saline followed by a $10 \%$ Formalin solution. The brains were embedded in parlodion, sectioned at $30-\mu$ in thickness, and stained with thionin.

\section{Results and Discussion}

Based on histological evidence, one animal in the nucleus circularis group was eliminated from all data analyses. This subject's lesions were in the posterior hypothalamus. All other subjects in this group had lesions restricted to the area of the nucleus circularis. Of these nine subjects, five had unilateral damage of the nucleus circularis with contralateral damage 
within .1 to $.2 \mathrm{~mm}$ of the nucleus. The one exception was a subject with unilateral damage of the nucleus circularis and a contralateral lesion $.5 \mathrm{~mm}$ lateral of the nucleus. The remaining four subjects had bilateral lesions .1 to $.3 \mathrm{~mm}$ from the posteriolateral border of the nucleus circularis. The extent of the damage was slightly greater than that produced by Harrell et al. (1978). This difference was a result of increasing the duration of the lesioning current from 1 to $2 \mathrm{sec}$. The lesions, however, were discrete and did not damage the paraventricular nucleus, supraoptic nucleus, or preoptic area. An example of the damage produced is shown in Figure 1. The lateral preoptic lesions were within the boundaries of this nucleus, and no other area was affected. An example of the damage produced in the lateral preoptic nucleus is provided in Figure 2.

The mean amount consumed over the $60 \mathrm{~min}$ following isotonic saline injection for the sham, lateral preoptic, and nucleus circularis group was 2.8, 2.6, and $2.0 \mathrm{ml}$, respectively. The nucleus circularis group drank the least, but this difference was not significant $[F(2,26)=.585, p<.56]$. The mean amount consumed following hypertonic saline injection for the sham, lateral preoptic, and nucleus circularis group was $8.4,8.3$, and $4.5 \mathrm{ml}$, respectively. This difference was highly statistically significant $[F(2,26)$ $=10.13, \mathrm{p}<.0006]$, indicating a decrement in response to hypertonicity by nucleus circularis lesioned subjects. Even though the mean amount consumed by the nucleus circularis group following isotonic saline injection was not significantly different from that of the other two groups, the common pattern observed under isotonic and hypertonic conditions might cause some concern that the results reflect a general response deficit or overall decrease in thirst. Although an overall decrease in thirst would still support a role for the nucleus circularis in thirst, the purpose of the present study was to determine any

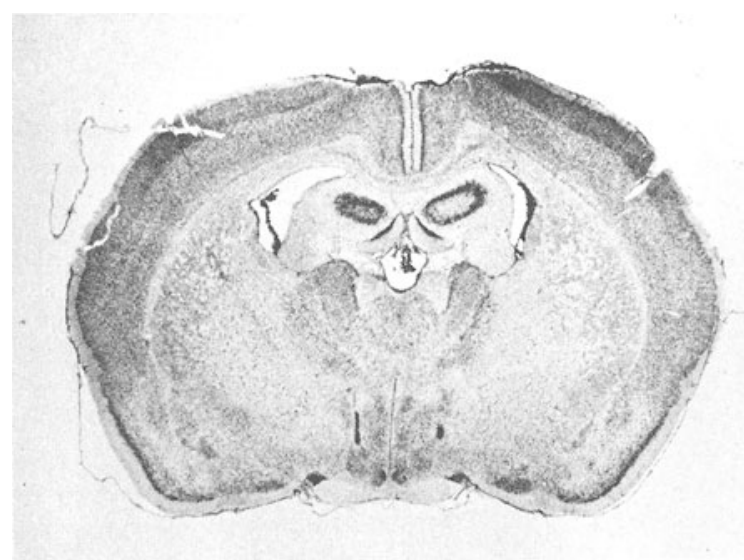

Figure 1. An example of bilateral destruction in nucleus circularis lesioned subjects.

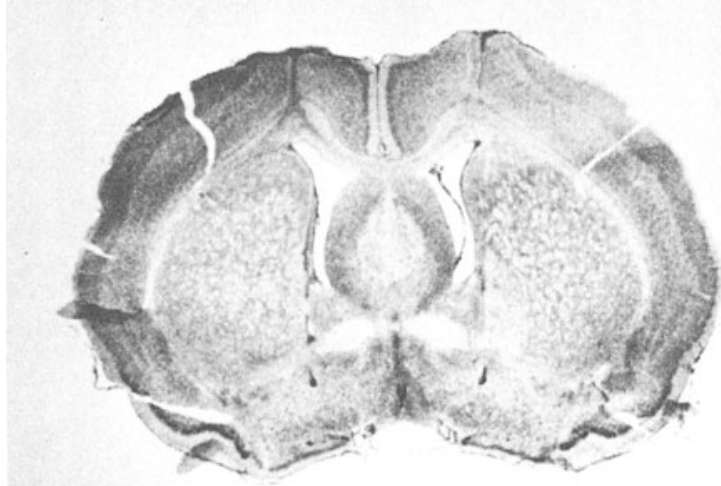

Figure 2. An example of bilateral destruction in lateral preoptic lesioned subjects.

differences specific to osmotic thirst. This would best be demonstrated by regarding the amount consumed following isotonic injection as a baseline and then computing difference scores between isotonic and hypertonic conditions as the measure of response to altered tonicity.

Difference scores were computed at each 10-min period for $1 \mathrm{~h}$ postinjection by subtracting the amount consumed up to that time following isotonic saline injection from that consumed following hypertonic saline injection. Inspection of the graphic representation of the results in Figure 3 shows an apparent deficit in osmotic thirst in the nucleus circularis lesioned group. A $3 \times 6$ analysis of variance with one repeated measure supported this conclusion. This analysis produced a significant groups $x$ measurement interval interaction $[F(10,130)=2.43$, $\mathrm{p}<.02$ ], a significant main effect of measurement interval $[F(5,30)=71.5, p<.001]$, and a nonsignificant main effect of groups $[F(2,23)=2.11, p<.14]$.

The basic hypothesis of Experiment 1 was that rats with small lesions in the area of the nucleus circularis would consume less water in a 1-h period than would rats with small lesions in the lateral preoptic nucleus or sham-operated animals following intraperitoneal injections of hypertonic saline. This hypothesis was supported. In addition, it was found that rats with small lesions in the lateral preoptic nucleus did not differ significantly from the sham-operated group and were, in fact, behaviorally indistinguishable. The sham-operated subjects in the present study responded with a magnitude that was comparable to that displayed by the sham-operated animals employed by Harrell et al. (1978), thus providing consistency of controls between the current study and the only prior research to take behavioral measures of the influence of the nucleus circularis on osmotic thirst. Results from Experiment 1 lend strong support to Verney's (1947) conclusion that osmorecep- 


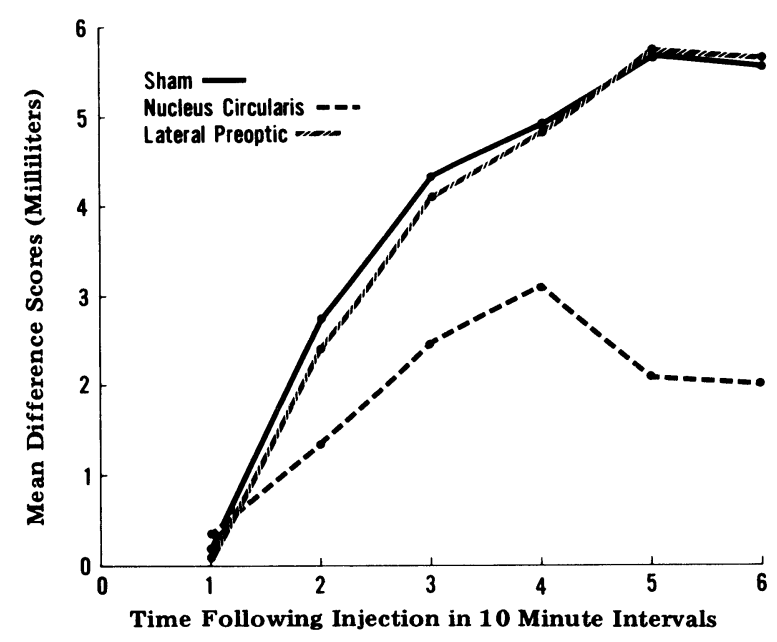

Figure 3. Difference scores for nucleus circularis, lateral preoptic, and sham-operated rats at 10 -min intervals. Scores were computed by subtracting the amount of water consumed up to that time following isotonic injection from the amount consumed following hypertonic saline injection.

tors are located in the vascular bed supplying the supraoptic nucleus and to Hatton's (1976) proposal that the nucleus circularis could be such an osmoreceptor. In addition, data from the present study do not provide an indication of a deficit in osmotic thirst following discrete lesions in the lateral preoptic nucleus. The possibility exists that slightly larger lesions in the lateral preoptic might produce a decrement and still be small enough to provide information about the location of concentrated osmosensitive cells.

\section{EXPERIMENT 2}

The purpose of Experiment 2 was to determine whether any deficit in osmotic thirst would be produced by lateral preoptic lesions intermediate in size between the small lesions in Experiment 1 and the large lesions employed in previous research.

\section{Method}

Subjects. The subjects were 20 approximately $350-8$, male, albino Sprague-Dawley rats. They were individually housed and given food and water ad lib except for the 2-h period preceding each test session.

Procedure. By random assignment, the subjects were divided equally into a lateral preoptic lesioned group and a control group. The lesion placement for the lateral preoptic group was exactly as that in Experiment 1, and the current parameters were $2 \mathrm{~mA}$ for $5 \mathrm{sec}$. The procedure for testing was identical with that in Experiment 1.

\section{Results and Discussion}

The mean amount consumed over the $60 \mathrm{~min}$ following isotonic saline injection for the control and lateral preoptic group was 1.1 and $1.8 \mathrm{ml}$, respectively. This difference was not statistically significant $[F(1,14)=2.29, p<.15]$ and is in the opposite direc- tion of the pattern observed in Experiment 1 following isotonic saline injection. The mean amount consumed following hypertonic saline injection for the control and lateral preoptic group was 7.4 and $5.1 \mathrm{ml}$, respectively. This difference was not statistically significant $[F(1,14)=2.99, p<.10]$. Thus, a group with intermediate-sized lesions of the lateral preoptic do not show a decrement in amount consumed following osmotic challenge, even though the results approach significance. Again, difference scores were computed as in Experiment 1. In this case, one might attribute the differences in the lateral preoptic group to results from a slightly greater consumption after isotonic injection rather than to a decrease after hypertonic injection. However, the differences following isotonic injection were not significant, and therefore the use of difference scores was deemed to be appropriate.

Difference scores for the control group increased over time; however, the lateral preoptic lesioned group showed little change (Figure 4 ). The increase across measurement intervals for the control subjects was almost identical to that of the sham-operated groups in Experiment 1 and that found in the Harrell et al. (1978) study. The deficit in the lateral preoptic group was statistically significant. A $2 \times 6$ analysis of variance of the difference scores produced a significant main effect for measurement interval $[F(5,70)=$ $32.08, p<.001]$, a significant interaction $[F(5,70)=$ $3.60, \mathrm{p}<.006]$, and a near-significant main effect for groups $[F(1,14)=4.06, p<.064]$.

As shown in Figure 5, the damage was largely restricted to the lateral preoptic nucleus, although in some cases the anterior hypothalamus was damaged. The two animals in the lesion group that showed the

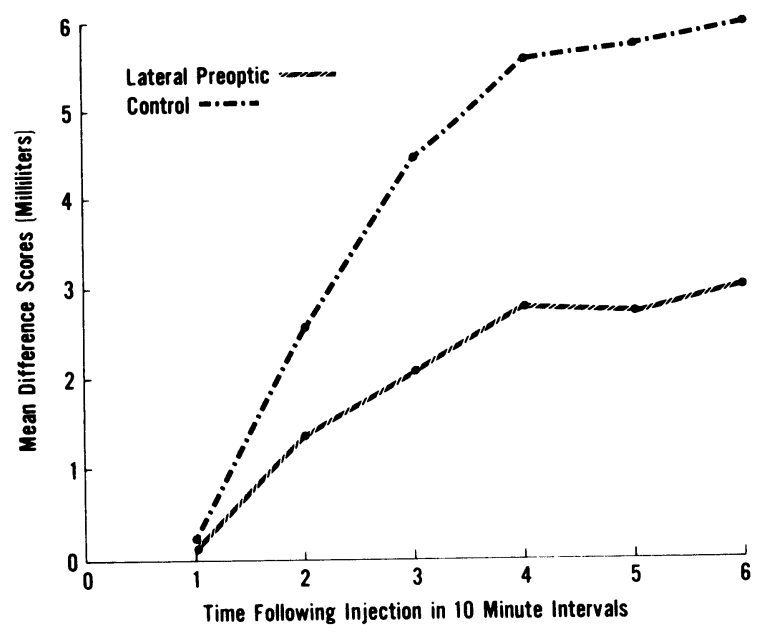

Figure 4. Difference scores for subjects with moderate-sized lateral preoptic lesions and controls at $10-\mathrm{min}$ intervals. Scores were computed by subtracting the amount of water consumed up to that time following isotonic saline injection from the amount consumed following hyptertonic saline injection. 


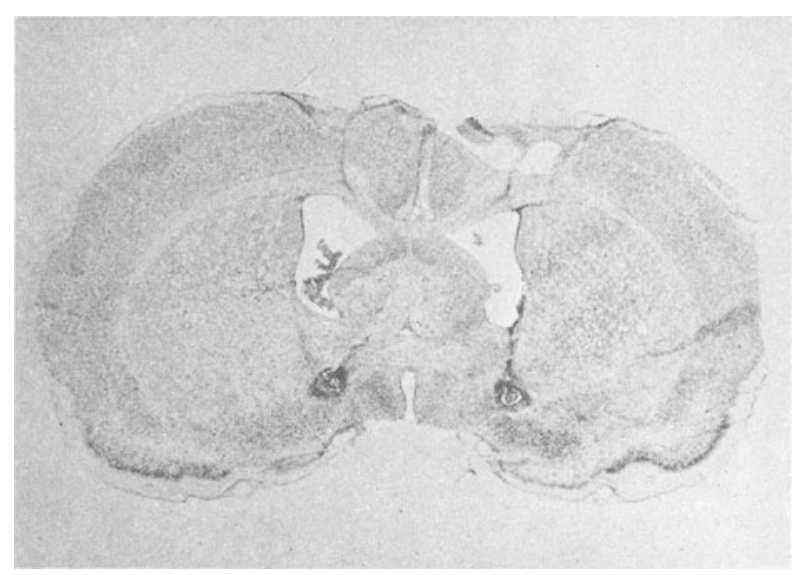

Figure 5. An example of bilateral destruction produced by moderate-sized lesions in the lateral preoptic nucleus.

greatest deficit had lesions that extended posteriorly to the anterior hypothalamus, whereas the two subjects that showed no deficit had lesions that did not extend posteriorly beyond the anterior commissure. Of the remaining four subjects, three had lesions intermediate between these extremes in both anteriorposterior location of damage and response deficit. One subject with lesions involving the anterior hypothalamus had an intermediate response deficit. Even the most posterior lesions did not damage the nucleus circularis. These data suggest that a deficit in osmotic thirst was produced only by moderately sized lesions that extended past the posterior border of the anterior commissure and into the anterior hypothalamus.

\section{GENERAL DISCUSSION}

In agreement with Harrell et al. (1978), these data support the hypothesis that osmosensitive cells are highly concentrated in the area of the nucleus circularis (Hatton, 1976). These findings are also consistent with Verney's (1974) localization of osmoreceptor cells to the supraoptic area. Deficits in osmotic thirst have been produced in other hypothalamic areas, but only with substantially larger lesions, which suggests very diffusely represented osmosensitive cells. Based on the histologies from these studies, their results might be attributable to damage extending to the area of the nucleus circularis.

However, the results of Experiment 2 demonstrate that a deficit in osmotic thirst, as measured by difference scores, can be produced by moderate-sized lesions of the lateral preoptic that do not damage the nucleus circularis, but only when the damage extends to the anterior hypothalamus. This is consistent with the findings of Peck and Novin (1971), who note that their lesions of the lateral preoptic nucleus, which were effective, destroyed more tissue than seemed reasonable and that lesions rostral to the anterior commissure were ineffective. Thus, the results of Experiments 1 and 2, taken together, suggest that the density of osmosensitive cells is great in the area of the nucleus circularis and, in agreement with previously cited studies, that these cells become more diffusely represented in the preoptic.

The diffuse representation of osmoreceptor cells in the lateral preoptic area and the fact that rats with lesions restricted to the lateral preoptic show appropriate behavioral responses to dehydration raise questions about the functional significance of this area for the control of osmotic thirst (Coburn \& Stricker, 1978). Also, deficits in thirst following large lesions of the lateral preoptic hypothalamus suggest not alterations of receptor mechanisms but, rather, second-order effects (Blass \& Epstein, 1971; Malmo \& Mundl, 1975; Tondat \& Almli, 1976). In contrast, the functional significance of the area of the nucleus circularis is indicated by behavioral deficits following very small lesions and by intracellular changes following water deprivation (Harrell et al., 1978; Hatton, 1976; Tweedle \& Hatton, 1976). However, the lateral preoptic may have increased influence on osmotic thirst in long-term deprivation because effects of stimulation of the nucleus circularis last 20 min, whereas stimulation of the lateral preoptic may persist for hours (Blass \& Epstein, 1971; Hatton, 1976; Peck \& Novin, 1971).

Another possible interpretation of the deficits produced following damage to the area of the nucleus circularis is that critical tracts enpassant were damaged. Coburn and Stricker (1978) proposed that the effect following lateral preoptic lesions might be due to damaging monaminergic pathways. In fact, our data demonstrate that deficits occur when the nucleus is only partially damaged. If fiber tracts become more concentrated in a rostrocaudal direction, then smaller lesions might be more effective as they are moved toward the supraoptic area. It is also possible that lesions damaged the fibers that course laterally from the sensory cells in the nucleus circularis to the supraoptic nucleus.

Even though our data are consistent with Hatton's (1976) proposal that the nucleus circularis is an osmoreceptor in the supraoptic area like that suggested by Verney (1947), the functional role of this area is unclear. The structural characteristics and cellular changes do seem to support a sensory role for the neurons of the nucleus circularis, but the demonstration of intracellular generator potentials following dehydration would strengthen this conclusion. Also, the interaction between the nucleus circularis and supraoptic has not been documented. The interrelationship of the nucleus circularis and other hypothalamic areas that influence osmoregulation must 
also be investigated. It is known that $\mathrm{ADH}$ secretion is affected by a variety of such stimuli as pain, cold, and dehydration. Determining the functional role of various hypothalamic areas is required for an explanation of osmoregulation. The nucleus circularis may be more responsive to dehydration itself, whereas the temperature-sensitive preoptic area may affect ADH secretion more in response to cold (Szymusiak \& Satinoff, 1982). Consistent with this speculation, lesions of the lateral preoptic do not interfere with dehydration-induced ADH release, although medial preoptic lesions that do impair ADH secretion in response to hyperosmolarity invade the anterior hypothalamus but do not appear to damage the supraoptic area (Gemert, Miller, Carey, \& Moses, 1975). In conclusion, although an exact mapping of osmoreceptor cells in the hypothalamus is not clear, the area of the nucleus circularis appears to be osmosensitive and to influence thirst-motivated behavior.

\section{REFERENCE NOTE}

1. Harrell, E. H., Lambert, P. L., \& Ivy, D. Effect of nucleus circularis lesions on osmotic thirst. Paper presented at the Southwestern Psychological Association, Oklahoma City, April 1978.

\section{REFERENCES}

ANDE Rsson, B. Thirst and brain control of water balance. American Scientist, 1971, 59, 408-415.

Andersson, B., Leksell, L. G., \& Lishajko, F. Perturbations in fluid balance induced by medially placed forebrain lesions. Brain Research, 1975, 99, 261-275.

Bandaranayake, R. C. Morphology of the accessory neurosecretory nuclei and the retrochiasmatic part of the supraoptic nucleus of the rat. Acta Anatomica, 1971, 30, 14-22.

Blass, E. M., \& Epstein, A. N. A lateral preoptic osmoreceptive zone for thirst in the rat. Journal of Comparative and Physiological Psychology, 1971, 76, 378-394.

Buggy, J., \& Johnson, A. K. Preoptic-hypothalamic periventricular lesions: Thirst deficits and hypernatremia. American Journal of Physiology, 1979, 233, R75-R82.

Brody, M. J., \& Johnson, A. K. Role of the anterioventral third ventricle (AC3C) region in fluid and electrolyte balance, arterial pressure regulation, and hypertension. In L. Martin \& W. D. Ganons (Eds.), Frontiers in neuroendocrinology. New York: Raven Press, 1980.

Coburn, P. D., \& Stricker, E. M. Osmoregulatory thirst in rats after lateral preoptic lesions. Journal of Comparative and Physiological Psychology, 1978, 92, 350-361.
Cross, B. A., \& Green, J. D. Activity of single neurones in the hypothalamus: Effect of osmotic and other stimuli. Journal of Physiology, 1959, 148, 554-569.

Gemert, M., Miller, M., Carey, R. J., \& Moses, A. M. Polyuria and impaired ADH release following medial preoptic lesioning in the rat. American Journal of Physiology, 1975, 228, 1293-1297.

Gregoretri, L. Contribution à l'étude du noyau supraoptique accessoire de l'homme. Acta Neuroveg, 1954, 10, 1-20.

Hatton, G. I. Nucleus circularis: Is it an osmoreceptor in the brain? Brain Research Bulletin, 1976, 1, 123-131.

Johnson, A. K., \& BugGY, J. A. A critical analysis of the site of action for the dipsogenic effect of angiotensin II. In J. P. Buckley \& C. Ferrario (Eds.), International Symposium on the Central Actions of Angiotensin and Related Hormones. Oxford: Pergamon Press, 1977.

LAQUEUR, G. L. Neurosecretory pathways between the hypothalamic paraventricular nucleus and the neurohypophysis. Journal of Comparative Neurology, 1954, 101, 543-563.

Malmo, R. B., \& Munde, W. J. Osmosensitive neurons in the rat's preoptic area: Medial-lateral comparison. Journal of Comparative and Physiological Psychology, 1975, 88, 161-175.

Martin, J. R., Geiselman, P. J., \& Novin, D. Drinking to intracellular dehydration following vagotomy in rats. Physiology \& Behavior, 1979, 23, 527-537.

Peck, J. W., \& Blass, E. M. Localization of thirst and antidiuretic osmoreceptors by intracranial injections in rats. American Journal of Physiology, 1975, 5, 1501-1509.

PECK, J. W., \& Novin, D. Evidence that osmoreceptors mediating drinking in rabbits are in the lateral preoptic area. Journal of Comparative and Physiological Psychology, 1971, 74, 134-147.

Peterson, R. P. Magnocellular neurosecretory centers in the rat hypothalamus. Journal of Comparative Physiology, 1966, 128, 181-190.

Sherlock, D. A., Field, P. M., \& Raisman, G. Retrograde transport of horseradish peroxidase in the magnocellular neurosecretory system of the rat. Brain Research, 1975, 88, 403-414.

Szymusiak, R., \& Satinoff, E. Acute thermoregulatory effects of unilateral electrolytic lesions of the medial and lateral preoptic area in rats. Physiology \& Behavior, 1982, 28, 161-170.

Teitelbaum, P., \& Epstein, A. N. The lateral hypothalamic syndrome: Recovery of feeding and drinking after lateral hypothalamic lesions. Psychological Review, 1962, 69, 74-90.

Tondat, L. M., \& Almli, C. R. Evidence for independent osmosensitivity of lateral preoptic and lateral hypothalamic neurons. Brain Research Bulletin, 1976, 1, 241-249.

Tweedle, C. D., \& HatTon, G. I. Ultrastructure comparisons of neurons of supraoptic and circularis nuclei in normal and dehydrated rats. Brain Research Bulletin, 1976, 1, 103-121.

VERNEY, E. B. Antidiuretic hormone and the factors which determine its release. Proceedings of the Royal Society of London, 1947, 135B, 25-106.

von Euler, C. A. Preliminary note on slow hypothalamic osmopotentials. Acta Physiologica Scandinavica, 1953, 29, 133-136.

(Manuscript received July 14, 1982;

revision accepted for publication June $15,1983$. 